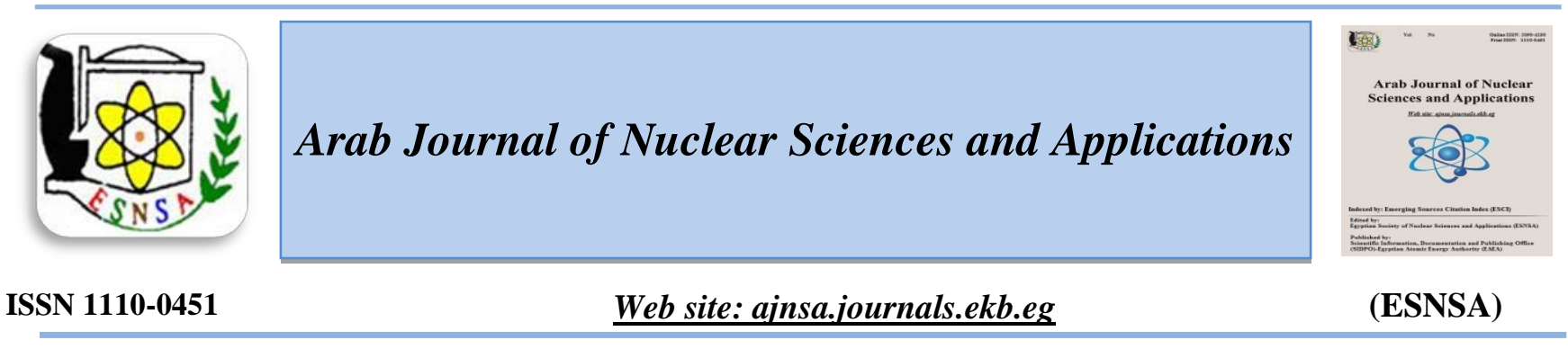

\title{
Determination of Temperature Feedback Coefficients for OPR-1000 Fuel Assembly Using Adjusted Cross Section Libraries
}

\author{
Mohga Hassan \\ Safety Engineering Department, Nuclear and Radiological Regulatory Authority, Cairo, Egypt
}

Received $2^{\text {nd }}$ Oct. 2019 Accepted $15^{\text {th }}$ March 2020

\begin{abstract}
An important source of reactivity variation in an operating reactor is the change in the temperature of the system. This change affects the criticality of the reactor and is expressed by the temperature reactivity coefficients. The most important feedback coefficients are those caused specifically by fuel and by moderator temperature changes. In this paper, temperature reactivity feedback coefficients are calculated for two solid assemblies $16 \times 16$ and annular $12 \times 12$, designed for OPR-1000 reactor. Feedback coefficients calculated are the fuel temperature coefficient, moderator temperature coefficient, prompt reactivity coefficient and power coefficient. A thermal resistance model was adapted to solid and annular fuel and was used to calculate the power coefficient. MCNP6 code was used to determine the multiplication factor, and hence the feedback coefficients. Temperature adjusted libraries were produced using MAKXSF utility program, associated with MCNP6 code. The difference between the use of regular library and temperature adjusted one is clarified. It was assumed that both reactors, with either fuel assembly type, operate at $\mathbf{1 0 0} \%$ power. The results showed that both designs gave close values with better results of annular fuel for the prompt reactivity and power coefficients.
\end{abstract}

Keywords: Annular fuel, Reactivity Feedback, Temperature Adjusted Libraries

\section{Introduction}

One of the most significant factors influencing reactor operation safety is the temperature effect on reactivity. At reactor startup, meaning at very low power level, the flux level is proportional to the reactor power. At higher power levels, and as temperatures rises, the densities of the core materials change at different rates, and as a consequence, the microscopic reaction rates. These changes affect the multiplication factor, causing temperature-related reactivity feedback effects to proceed. This results in the addition of either positive or negative reactivity and hence changes in reactor power [1].

The temperature coefficient is the relative change of a physical property with respect to change in temperature, and it is used to assess the inherent safety of a reactor. Doppler broadening of the resonance capture cross section of the fertile material accounts for the dominant part of the fuel temperature. The phenomenon is expressed by the fuel temperature coefficient (FTC) or Doppler coefficient, and it is of the highest importance in the reactor stability. In light water reactors, the change in moderator temperature changes its physical density as well as the thermal neutron spectrum, which in turn affects the multiplication factor. Moderator temperature coefficient (MTC) represents reactivity feedback resulting mainly from moderator density change, following its temperature variation [2].

Beside the above two coefficients there are two composite reactivity coefficients that are affected by the thermo physical properties of the fuel

Corresponding author: mohg01@yahoo.com

DOI: 10.21608/ajnsa.2020.17701.1280

(C) Scientific Information, Documentation and Publishing Office (SIDPO)-EAEA 
material, as well as the amount of fuel present; namely "prompt reactivity coefficient", and "power coefficient". The prompt reactivity coefficient is dominant in the event of large reactivity insertion over a very short period of time, such as power excursions. The power coefficient is defined as the variation of reactivity caused by the single power variation. Power coefficient is applicable in case of increase in reactor power from a few percent, of its rated power, to full power, or during power maneuver [1].

The OPR-1000 was originally designated as the Korean Standard Nuclear Power Plant, (KSNP+) and was re-designated as the OPR-1000 in 2005 for foreign sales [3]. The core of the OPR1000 is designed to generate 2,825 MWt (1050 MWe). The reactor core is composed of 177 fuel assemblies and 73 control element assemblies. The fuel assembly contains 236 fuel rods in a $16 \times 16$ array. Previous studies suggested replacing the solid fuel with annular fuel, specifically a $12 \times 12$ fuel assembly. For, example, Liang Zhang( 4) showed that compared to the traditional solid fuel geometry for PWRs, the internally and externally cooled annular fuel offers the potential to increase the core power density while maintaining or increasing safety margins. It was demonstrated that for the Korean OPR-1000 reactor, the power density can be increased by $20 \%$ when the $16 \times 16$ solid fuel assemblies are replaced by $12 \times 12$ annular fuel assemblies, the study also included a full core analysis for the use of annular fuel with variable enrichments for fuel and gadolinium use. The results of the previous study were supported by another parametric study [5] where the feasibility of $120 \%$ core power was assessed. This parametric study was carried out for the fuel rod dimension, gap conductance, thermal diffusion coefficients, and pressure loss of the spacer grids. None of these studies considered the composite reactivity feedback effects.

The prompt reactivity coefficient and power coefficient were investigated for two arrangements of annular fuel; $13 \times 13$ assembly for PWR [6], and hexagonal lattice for VVER [7]. . Both studies used regular cross section data libraries that are associated with MCNP code. In the first study the use of standard MCNP library resulted in feedback coefficients with variable trend, in the second a single value of every coefficient was determined The choice of the appropriate cross section library that matches the specified temperature is essential in neutronic studies. Regular libraries, associated with MCNP6 code [8], are processed at certain temperatures and during calculations one has to select the library processed at a temperature close to that used in the calculations, and this may lead to inaccurate results. The MAKXSF code [9] is a utility program for manipulating cross-section library files, for MCNP5 and MCNP6 codes. It can be used to create nuclide datasets at new temperatures, resulting in a temperature-dependent library for a specific application. Creation of a nuclide dataset at a new temperature involves 3 basic operations:

- Doppler broadens the resolved resonance data to a higher temperature.

- Interpolates any unresolved resonance probability tables to the new temperature.

- Interpolates $S(\alpha, \beta)$ thermal scattering kernel data to the new temperature.

In the present work, the MAKXSF code is used to create adjusted temperature-dependent libraries to cope exactly with the different temperature values used in the calculations. The difference between the use of regular libraries and temperatureadjusted libraries will be investigated. The temperature feedback coefficients are determined taking into account variation of fuel properties with temperatures. Factors that are considered to be variable with temperature are fuel heat capacity, fuel thermal conductivity, and fuel thermal resistance. In addition, since the gap resistance occupies a great part of the total heat resistance of fuel element [10], a thermal resistance model that takes into account the gap resistance is adapted in the present work.

\section{Assembly Description}

The reference OPR-1000 fuel assembly has a $16 \times 16$ array with 236 solid fuel rods, 4 guide tubes for control rods and a central guide tube for instrumentation. On the other hand, the annular fuel assembly consists of a $12 \times 12$ array of 124 annular fuel rods, 4 control rod guide tubes and a central instrumentation tube. The annular fuel design is fully compatible with the solid fuel design in terms of structure, and coolant flow area. Besides, the guide tubes are of annular shape and their positions are compatible with the conventional design to match the control rod driving mechanism [4, 11]. Figure (1) illustrates the solid and annular assembly arrangement, and 
Figure (2) gives the fuel pins design detail. Their dimensions are listed in Table (1).
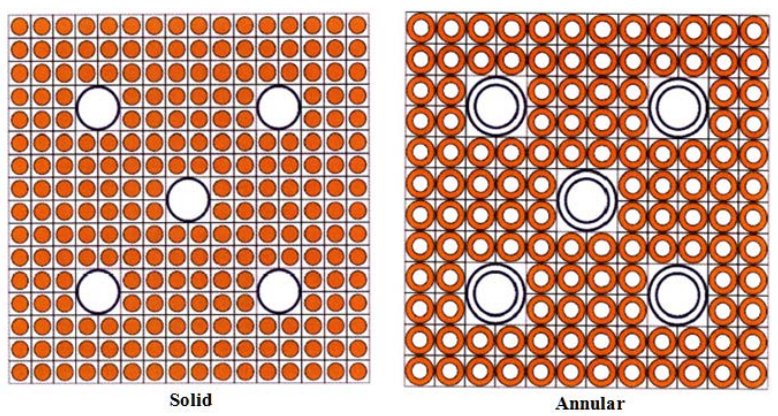

Figure (1): Solid and Annular Fuel Assembly Design
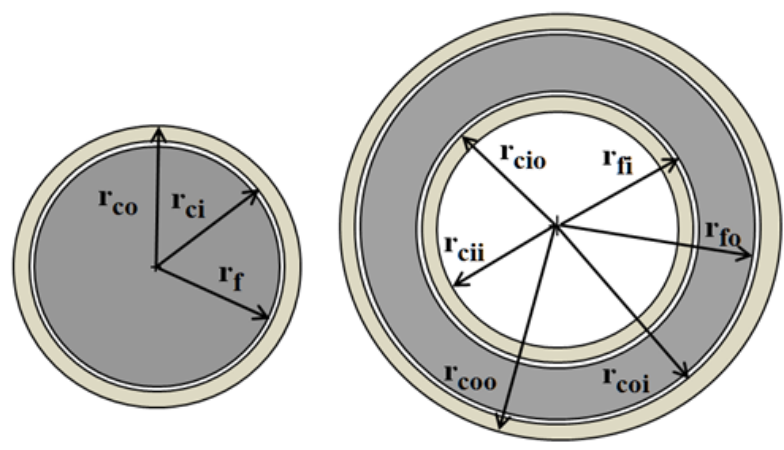

Solid

Annular

Figure (2): Solid and Annular Fuel Pin Design

Table (1): Fuel Assembly Dimensions

\begin{tabular}{ccc}
\hline & \multicolumn{2}{c}{ Dimension(cm) and Symbol } \\
\cline { 2 - 3 } & $\begin{array}{c}\text { Solid } \\
(\mathbf{1 6 \times 1 6})\end{array}$ & $\begin{array}{c}\text { Annular } \\
(\mathbf{1 2 \times 1 2})\end{array}$ \\
\hline Assembly Pitch & 20.78 & 20.78 \\
Pin Pitch & 1.285 & 1.713 \\
Inner Clad Inner Radius & - & $0.4400\left(\mathbf{r}_{\mathbf{c i i}}\right)$ \\
Inner Clad Outer Radius & - & $0.4970\left(\mathbf{r}_{\mathbf{c i o}}\right)$ \\
Pellet Inner Radius & - & $0.5040\left(\mathbf{r}_{\mathbf{f i}}\right)$ \\
Pellet Outer Radius & $0.4095\left(\mathbf{r}_{\mathbf{f}}\right)$ & $0.7260\left(\mathbf{r}_{\mathbf{f o}}\right)$ \\
Outer Clad Inner Radius & $0.4180\left(\mathbf{r}_{\mathbf{c i}}\right)$ & $0.7330\left(\mathbf{r}_{\mathbf{c o i}}\right)$ \\
Outer Clad Outer Radius & $0.4750\left(\mathbf{r}_{\mathbf{c o}}\right)$ & $0.7950\left(\mathbf{r}_{\mathbf{c o o}}\right)$ \\
Guide Tube Inner Radius & 1.1450 & 1.1450 \\
Guide Tube Outer Radius & 1.2450 & 1.2450 \\
Outer Tube Inner Radius & - & 1.5750 \\
Outer Tube Outer Radius & - & 1.6750 \\
\hline
\end{tabular}

\section{Model and Calculation Procedures}

Fuel temperature coefficient

The fuel temperature coefficient (FTC) is given by

$$
\alpha_{f}=\frac{1}{k} \frac{\partial k}{\partial T_{f}}
$$

Where $k$ is the multiplication factor and $\frac{\partial k}{\partial T_{f}}$ is the change of multiplication factor as a result of fuel temperature change or the slope of the curve that represent the relation between $k$ and $T_{f}$.

\section{Moderator temperature coefficient}

The moderator temperature coefficient (MTC) is given by [1]:

$$
\alpha_{m}=\frac{1}{k} \frac{\partial k}{\partial T_{c}}
$$

Where $k$ is the multiplication factor and $\frac{\partial k}{\partial T_{c}}$ is the change of multiplication factor as a result of moderator, or coolant, temperature change, or the slope of the curve that represent the relation between $k$ and $T_{c}$. since for light water reactors the coolant is the moderator we will refer to both as coolant.

\section{Composite coefficients}

The overall reactivity feedback can be expressed in terms of the average temperatures of fuel and coolant $\left(\bar{T}_{f e}, \bar{T}_{c}\right)[1]$ :

$$
d \rho_{f b}=\frac{1}{k} \frac{\partial k}{\partial \bar{T}_{f e}} d \bar{T}_{f e}+\frac{1}{k} \frac{\partial k}{\partial \bar{T}_{c}} d \bar{T}_{c}
$$

Where

$\rho_{f b} \quad$ is the reactivity feedback

$\bar{T}_{f e} \quad$ is the fuel average temperature, $\mathrm{K}$

$\bar{T}_{c} \quad$ is the coolant average temperature, $\mathrm{K}$

$k \quad$ is the effective multiplication coefficient

There is a number of situations for which a relationship can be derived, from the above equation, for the core-averaged temperatures. In this paper, focus is made on two important feedback coefficients used in analyzing power transients, namely prompt reactivity coefficient and the power coefficient.

\section{Prompt Reactivity coefficient}

In the event of large reactivity insertion over a very short period of time, heat transfer from fuel to coolant can be ignored, and the only feedback reactivity comes from heating of the fuel. In this case, the reactivity feedback is given by [12]:

$d \rho_{f b}=\frac{1}{k} \frac{\partial k}{\partial \bar{T}_{f e}} d \bar{T}_{f e}$ 
The change in power as a result of reactivity insertion can be given by [12]:

$$
P(t) d t=M_{f e} c_{p f e} d \bar{T}_{f e}
$$

Where

$M_{f e} \quad$ is the total mass of fuel elements, kg, and

$C_{p f e}$ is the fuel specific heat per unit mass, $\mathrm{J} /$ $\mathrm{kg} \mathrm{K}$

Combining equations 4,5

$d \rho_{f b}=\frac{1}{M_{f e} c_{f e}} \times \frac{1}{k} \frac{\partial k}{\partial \bar{T}_{f e}} \times P(t) d t=\mu \times P(t) d t$

Where:

$\mu=\frac{1}{M_{f e} c_{f e}} \times \frac{1}{k} \frac{\partial k}{\partial \bar{T}_{f e}}$

$\mu$ called the prompt reactivity coefficient.

In this work, the prompt reactivity coefficient is evaluated taking into account the variation of fuel specific heat with temperature. The fuel specific heat was calculated, for the range of temperatures considered in the study, using published correlation [13], the result is shown in Figure (3).

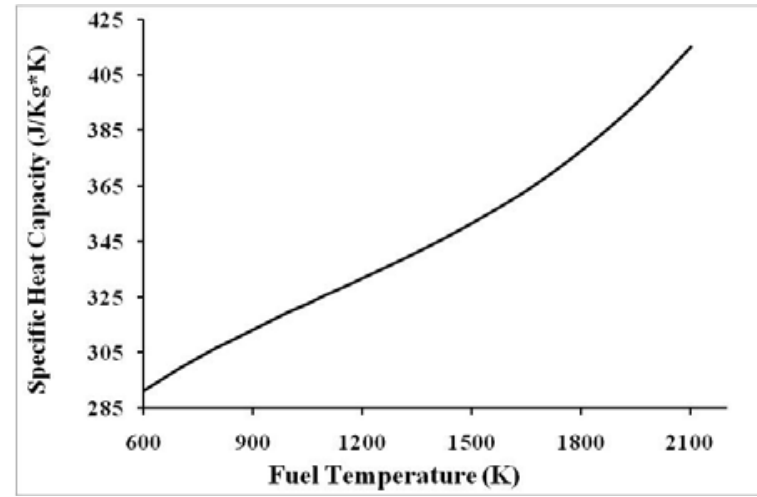

Figure (3): Fuel Specific Heat Capacity

\section{Power coefficient}

In the case of gradual increase in power the coolant temperature will change and its effect cannot be ignored. To obtain the power coefficient, we divide equation (3) by an incremental power change, $\mathrm{dP}$ [12]:

$\frac{d \rho_{f b}}{d P}=\frac{1}{k} \frac{\partial k}{\partial \bar{T}_{f e}} \frac{d \bar{T}_{f e}}{d P}+\frac{1}{k} \frac{\partial k}{\partial \bar{T}_{c}} \frac{d \bar{T}_{c}}{d P}$
Assuming that the power changes are slow, compared to the time required to remove heat from the fuel to the core outlet, the following steady state heat transfer relationship can be applied [12]:

$\bar{T}_{f e}-\bar{T}_{c}=R P$

And

$\bar{T}_{c}=\frac{P}{2 W c_{p c}}+T_{i}$

Where

$\mathrm{R} \quad$ is the fuel thermal resistance, $\mathrm{K} / \mathrm{W}$,

$\mathrm{P} \quad$ is the reactor thermal power, $\mathrm{W}$,

$\mathrm{W}$ is the total mass flow rate of the coolant through the assembly, $\mathrm{kg} / \mathrm{sec}$,

$c_{p c} \quad$ is the coolant specific heat, $\mathrm{J} / \mathrm{kg} \mathrm{K}$, and

$T_{i} \quad$ is the inlet coolant temperature, $\mathrm{K}$.

Differentiating equations (8) and (9) with respect to $\mathrm{P}$, and assuming that the coolant inlet temperature is constant, yields:

$\frac{d \bar{T}_{f e}}{d P}=R+\frac{1}{2 W c_{p c}}$

And

$\frac{d \bar{T}_{c}}{d P}=\frac{1}{2 W c_{p c}}$

Substituting equations (10) and (11) into equation (7):

$\frac{d \rho_{f b}}{d P}=\left(R+\frac{1}{2 W c_{p c}}\right) \frac{1}{k} \frac{\partial k}{\partial \bar{T}_{f e}}+\frac{1}{2 W c_{p c}} \frac{1}{k} \frac{\partial k}{\partial \bar{T}_{c}}$

Coolant specific heat was estimated as average for the range of temperatures under considerations, (table (2)). The fuel element thermal resistance will be deduced in the following.

\section{Fuel Element Thermal Resistance}

The fuel element thermal resistance is composed of fuel, gap, clad and coolant resistances.

Since the calculations are performed at BOC, there is no change in the gap size, and the helium in the gap is considered stagnant. Hence, it could be assumed that the heat transfer is steady state conduction in fuel, gap, and clad, and that convection only takes place in the coolant. Heat transfer is assumed to be in one direction, since the fuel element length is very large with respect to the 
fuel diameter. The thermal resistance model for both fuels is illustrated in Figure (4).

For Solid Fuel Element, the thermal resistance, $R_{S}$, is given by [14]:

$$
R_{S}=\frac{1}{2 \pi L}\left(\frac{1}{2 K_{f}}+\frac{\ln \left(r^{c_{c o}} / r_{f}\right)}{K_{g}}+\frac{\ln \left(r_{c o} / r_{c i}\right)}{K_{c}}+\frac{1}{r_{c o} h_{c}}\right)
$$

For annular Fuel Element, the thermal resistance, $R_{A}$, is given by [15]:

$$
\begin{gathered}
R_{A}=\frac{1}{2 \pi L}\left(\frac{1}{r_{c i i} h_{c}}+\frac{\ln \left({ }^{r_{c i o}} / r_{f i}\right)}{K_{g}}+\frac{\ln \left({ }^{r_{c i o}} / r_{c i i}\right)}{K_{c}}+\right. \\
\left.\frac{\ln \left({ }^{r_{f o}} / r_{f i}\right)}{K_{f}}+\frac{\ln \left(r_{c o i} / r_{f o}\right)}{K_{g}}+\frac{1}{r_{c o o} h_{c}}\right)
\end{gathered}
$$

Where

$K_{f} \quad$ is the thermal conductivity of fuel, W/m.K, $K_{c} \quad$ is the thermal conductivity of clad, $\mathrm{W} / \mathrm{m} . \mathrm{K}$,

$K_{g} \quad$ is the gap thermal conductivity, W/m.K, and

$h_{c} \quad$ is the coolant heat transfer coefficient, $\mathrm{W} / \mathrm{m}^{2} . \mathrm{K}$

The rest of terms are illustrated in Figure (2), values are in Tables, 1 and 4 .

Several parameters were required to perform calculations using the above models. Coolant parameters were calculated at the average temperature of the calculation range. Then, the heat transfer coefficient was calculated using Dittus-Boelter correlation [16], results are given in table (2). The thermal resistance was calculated as a function of fuel thermal conductivity, which was calculated using published correlation [17]. The resulting thermal conductivity curve for the range of temperatures considered in this study is shown in Figure (5).

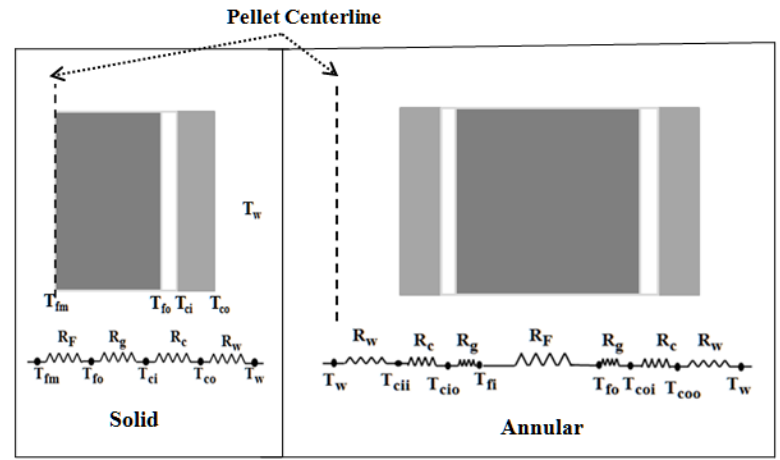

Figure (4): Thermal Resistance model
Clad thermal conductivity was calculated using the MATPRO equation [18] at $600 \mathrm{~K}$. The gap thermal conductivity value is taken at $600 \mathrm{~K}$ [19]. Values of parameters used in the study are stated in Table 2.

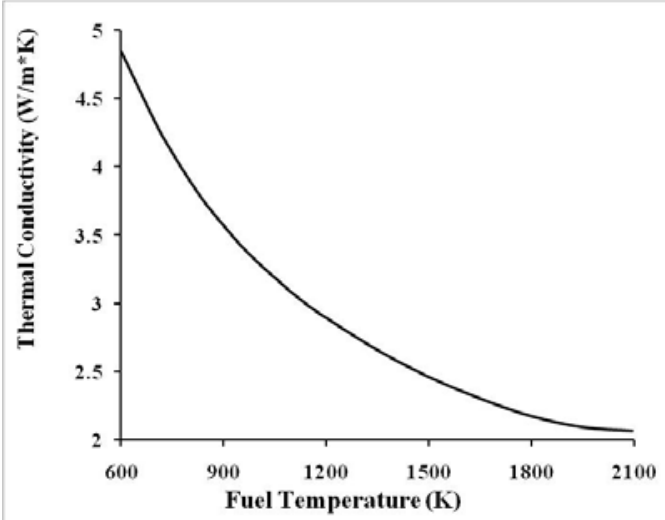

Figure (5): Fuel Thermal Conductivity

Table (2): Parameters Used in the Calculations

\begin{tabular}{ll}
\hline Parameter & Value \\
\hline Coolant $c_{p}(\mathrm{~J} / \mathrm{kg} \mathrm{K})$ & 6589 \\
Clad thermal conductivity $k_{c}(\mathrm{~W} / \mathrm{m}$ & 16.48672 \\
$\mathrm{~K})$ & 0.252 \\
Gap thermal conductivity $k_{g}(\mathrm{~W} / \mathrm{m} \mathrm{K})$ & 36980 for solid fuel \\
Coolant heat transfer coefficient & 42935 for annular \\
$h_{c}\left(\mathrm{~W} / \mathrm{m}^{2} \mathrm{~K}\right)$ & fuel \\
& 83.85 \\
Mass flow rate $(\mathrm{kg} / \mathrm{sec})$ & 492.64 for solid fuel \\
Fuel mass $(\mathrm{kg})$ & 421.49 for annular \\
& fuel \\
\hline
\end{tabular}

MCNP model and validation

A model was prepared using MCNP6 to simulate the two fuel assemblies, in order to estimate the multiplication factor. Because of its higher cooling efficiency annular fuel exhibits substantially lower peak temperature than the solid fuel [4]. So the normal operating temperature, at $100 \%$ power, is $600 \mathrm{~K}$ in comparison to $900 \mathrm{~K}$ in solid fuel. The normal coolant temperature for both cases was $585.4 \mathrm{~K}$, and the clad temperature is $600 \mathrm{~K}$. [11]. $\mathrm{K}_{\infty}$ values resulting from this model were compared to a previous model of the same assemblies, and the results are shown in Table (3). A previous study for annular fuel showed that the maximum temperature during a transient does not exceed $1200 \mathrm{~K}$ for annular fuel, while it can reach more than $2000 \mathrm{~K}$ for solid fuel [4, 5]. Therefore, temperatures ranges for this study were from 900 to $2100 \mathrm{~K}$ for solid fuel, and from 600 to $1200 \mathrm{~K}$ for annular fuel. For solid fuel the range was divided with $150 \mathrm{~K}$ steps, and $50 \mathrm{~K}$ steps for annular fuel. The range of temperature for coolant 
is 585.4 to $615 \mathrm{~K}$, which is the normal range in a PWR at $15 \mathrm{MPa}$ pressure, and the range was divided with $2.5 \mathrm{~K}$ steps.

To produce the required new libraries, input files, for the MAKXSF code, were prepared (input is called specs file) with the required temperatures. Multiple runs were performed using MAKXSF code, to produce the new libraries then, these libraries were introduced to the MCNP6 input files. Separate runs were performed using adjusted and regular libraries, for fuel and coolant temperature ranges.

Table (3): $\mathrm{K}_{\infty}$ Comparison

\begin{tabular}{cccc}
\hline $\begin{array}{c}\text { Assembly } \\
\text { Type }\end{array}$ & $\begin{array}{c}\text { Present } \\
\text { Study }\end{array}$ & $\begin{array}{c}\text { Previous } \\
\text { Study[8] }\end{array}$ & $\begin{array}{c}\text { Deviation } \\
\mathbf{\%}\end{array}$ \\
\hline $\begin{array}{c}\text { Solid 16x16 } \\
\text { Annular }\end{array}$ & 1.42284 & 1.418 & 0.34 \\
12x12 & 1.41043 & 1.40825 & 0.15 \\
\hline
\end{tabular}

\section{Results and Discussion}

Temperature adjusted libraries

The result for fuel temperature is shown in Figure (6). It can be seen that the regular library curve have a clear variable trend, while the adjusted temperature results are more reasonable.

On the contrary the resulting curve for $k_{\text {eff }}$ at variable coolant temperatures is almost the same for adjusted and regular libraries, as shown in Figure (7). That is because the range of temperature variation for coolant is small and close to the nearest regular library.

The use of the regular library results, especially in case of fuel temperature, could lead to erroneous results, because of the variation of slope of the $k$-T curve [6]. Thus, the rest of calculations will be performed using the adjusted library curves. By linear fitting to the adjusted library curve, we can calculate the slopes of the curve in each case, which will be used to calculate FTC, and MTC. The results are shown in table (4), this table also includes the determination coefficient $\left(\mathrm{R}^{2}\right)$ which represents the accuracy of the curve fitting [20], and ranges from 0 to 1 . The determination coefficient indicates very good representation of the fitted data.

Table (4): Slope of $\mathbf{k}_{\text {eff }}$ Curve

\begin{tabular}{ccc}
\hline Slope & Solid Fuel & Annular Fuel \\
\hline$\frac{\partial \boldsymbol{k}}{\boldsymbol{\partial} \bar{T}_{\boldsymbol{f} e}}$ & $-2.54 \mathrm{E}-05$ & $-3.48 \mathrm{E}-05$ \\
$\boldsymbol{\partial \boldsymbol { k }}$ & $\mathrm{R}^{2}=0.997$ & $\mathrm{R}^{2}=0.993$ \\
$\frac{\boldsymbol{\partial} \overline{\boldsymbol{T}}_{\boldsymbol{c}}}{2}$ & $-9.00 \mathrm{E}-04$ & $-7.84 \mathrm{E}-04$ \\
& $\mathrm{R}^{2}=0.98$ & $\mathrm{R}^{2}=0.976$ \\
\hline
\end{tabular}

Arab J. Nucl. Sci. \& Applic. Vol. 53, No. 2 (2020)
Fuel temperature coefficient

$\mathrm{ftc}$ variation for the range of temperature considered was calculated using equation (1). The results are shown in Figure (8), with an average of -1.82 and $-2.51 \mathrm{pcm} /{ }^{\circ} \mathrm{K}$, for solid and annular fuels respectively. This result is expected, since the fuel temperature coefficient is proved to be proportional to the surface to mass ratio [1] which is definitely higher for annular fuel.

\section{Moderator temperature coefficient}

MTC variation for the range of temperature considered was calculated using equation (2). The results are shown in Figure (9), with an average of $-68.32 \mathrm{pcm} /{ }^{\circ} \mathrm{K}$, and-56.12, for solid and annular fuels respectively.

The trend of the results of FTC and MTC commensurate with a previous study that compares solid with annular fuel [21]

\section{Prompt reactivity coefficient}

The prompt reactivity coefficient was calculated taking into account the change in FTC and fuel specific heat with temperature and the results are shown in Figure (10). It can be seen from this Figure that the prompt reactivity coefficient for annular fuel is more negative than that of solid fuel. The values of prompt reactivity coefficient are increasing towards less negative values only because the specific heat of the fuel increases with temperature (Figure (3)) resulting in the decrease of the first term of equation (6), $\frac{1}{M_{f e} c_{f e}}$, which lead to less negative values of the prompt reactivity coefficient. This can be further illustrated by considering the case with constant specific heat, in the same Figure, where the resulting coefficient is nearly constant, with a tendecy to increase negativity. However, the resulting values are still negative during the calculation range, which preserve the inherently safe design.

The results for power coefficient are illustrated in Figure (11). The power coefficient was calculated taking into account the variation of fuel thermal conductivity, as well as FTC, with temperature. The average value of MTC was used. In this case, as well, the annular fuel has higher negative values of power coefficient than the solid fuel, which proves the safe design. On the contrary, to prompt reactivity coefficient, the power coefficient decreases towards more negative values with increasing temperature. This is mainly because of 
the decrease of fuel thermal conductivity with temperature (Figure (5)), and next to that, because of the decrease in FTC with temperature. This can also be illustrated by considering the case with

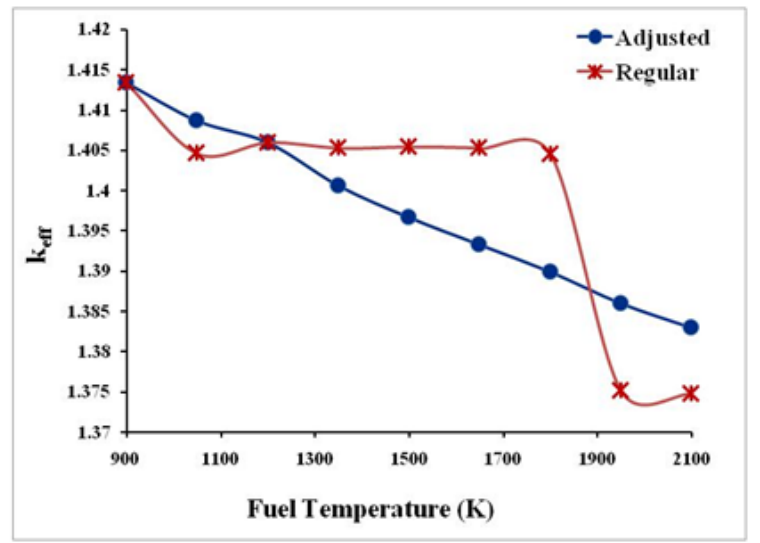

Solid Fuel constant thermal conductivity, where the values are nearly constant.

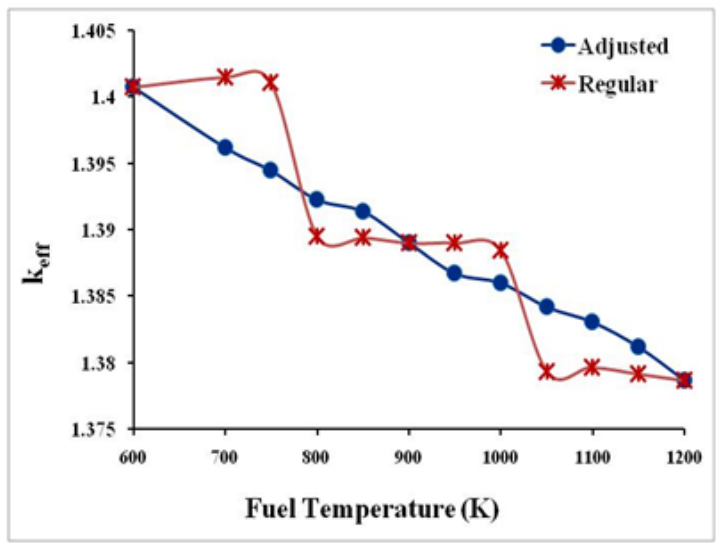

Annular Fuel

Figure (6): Variation of Effective Multiplication Factor with Fuel Temperature

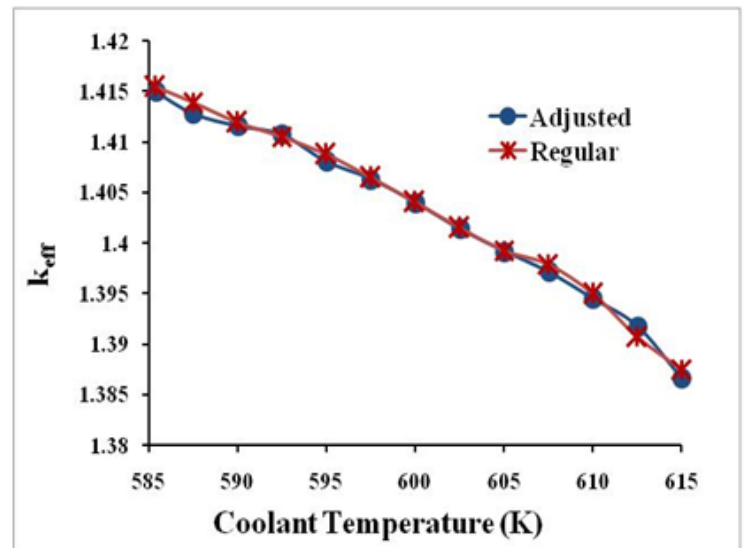

Solid Fuel

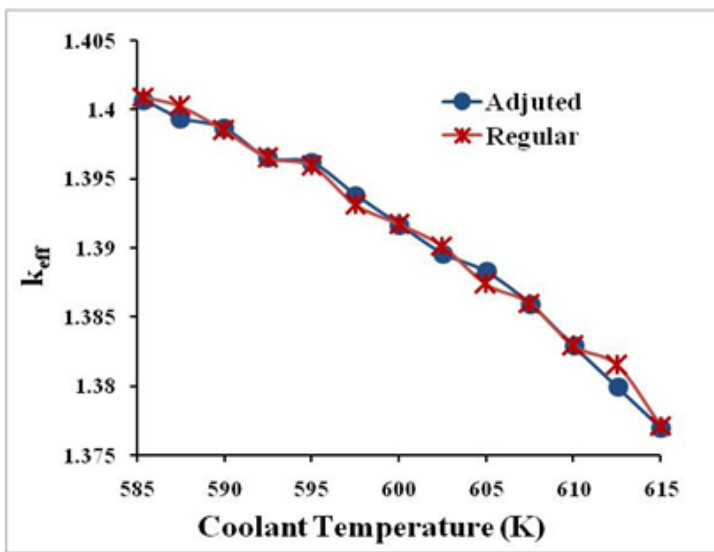

Annular Fuel

(7): Variation of Effective Multiplication Factor with Coolant Temperature 


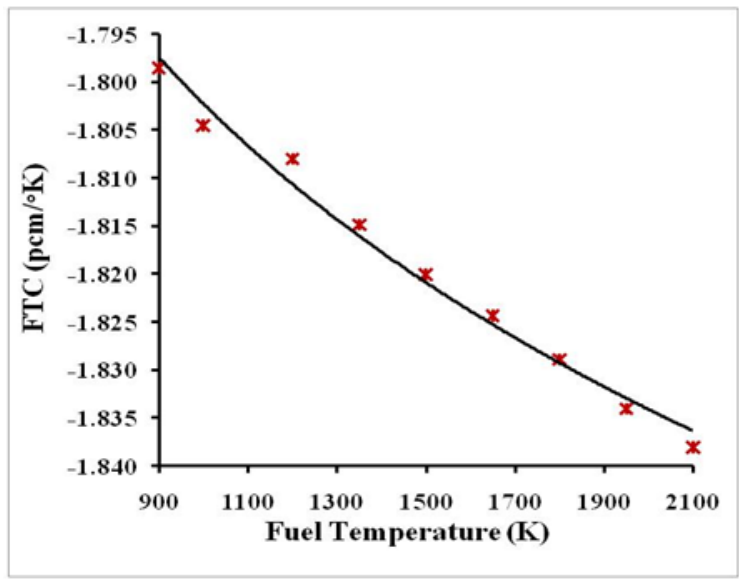

Solid Fuel

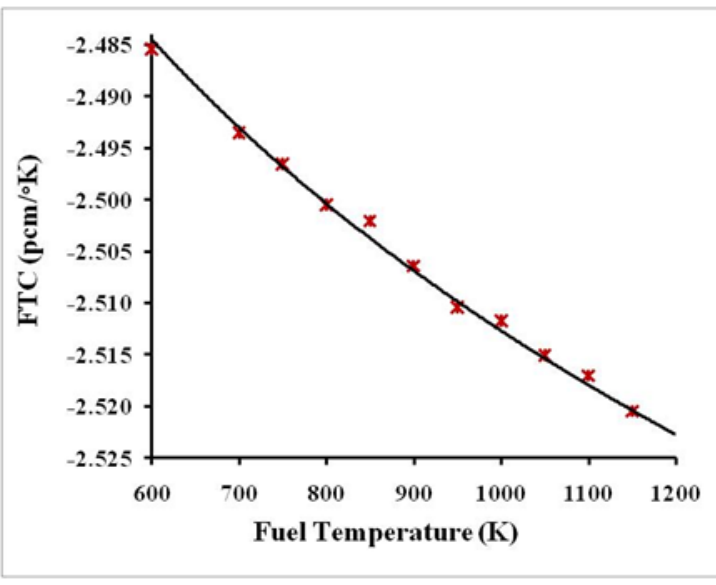

Annular Fuel

Figure (8): Variation of FTC with Fuel Temperature

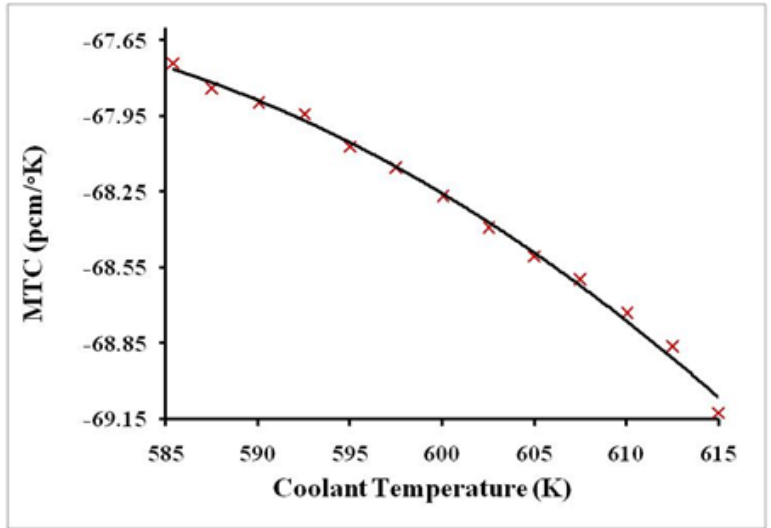

Solid Fuel

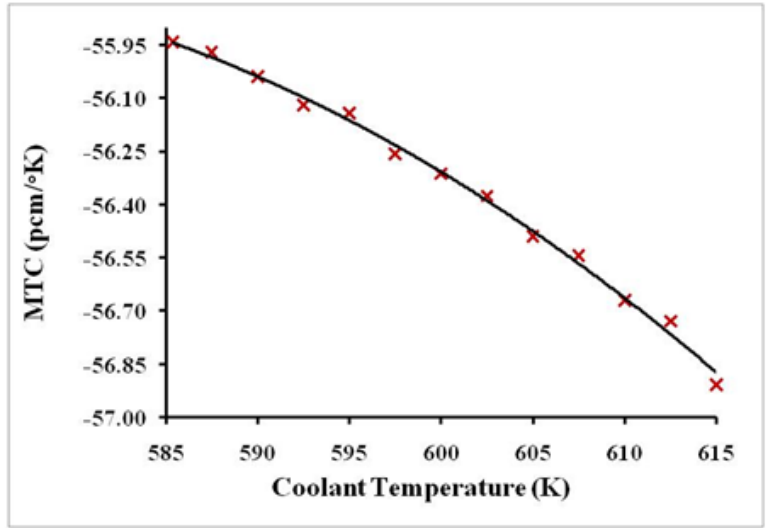

Annular Fuel

Figure (9): Variation of MTC with Coolant Temperature

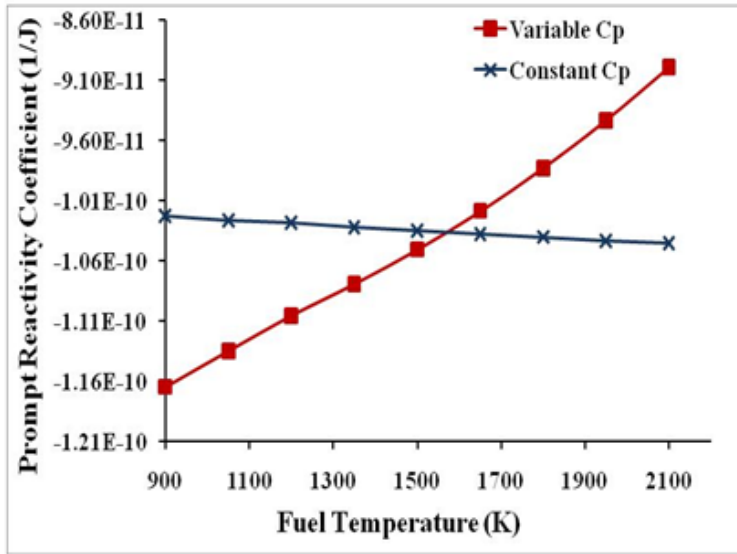

Solid Fuel

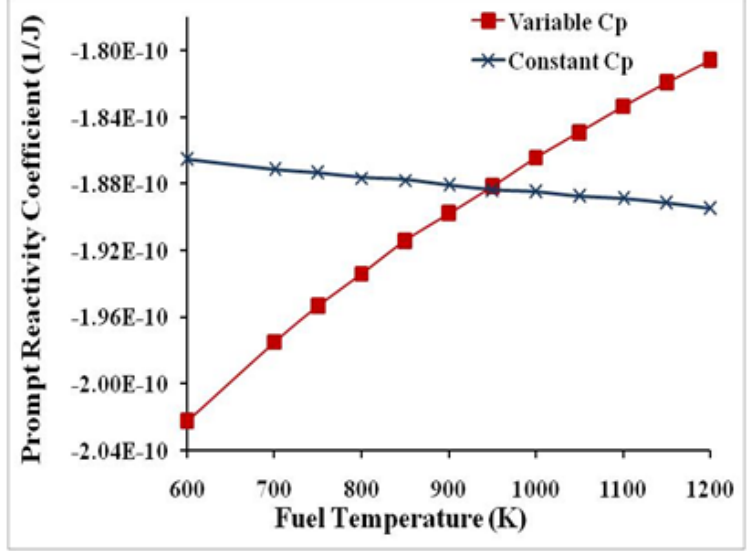

Annular Fuel

Figure (10): Prompt Reactivity Coefficient 


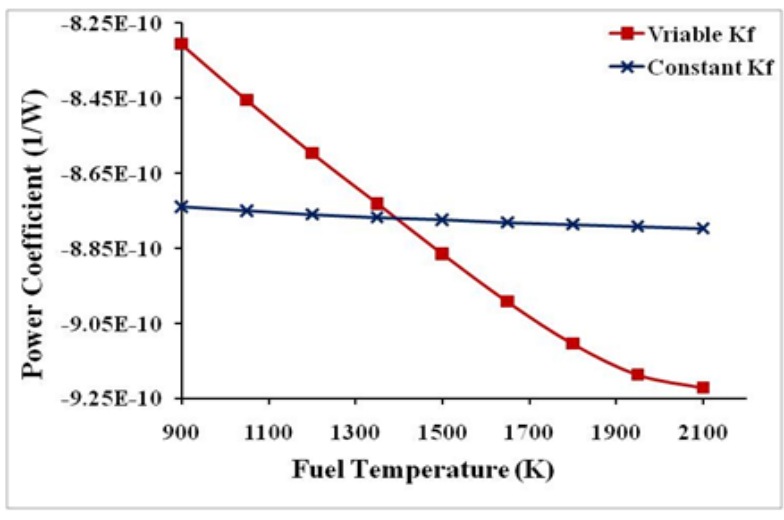

Solid Fuel

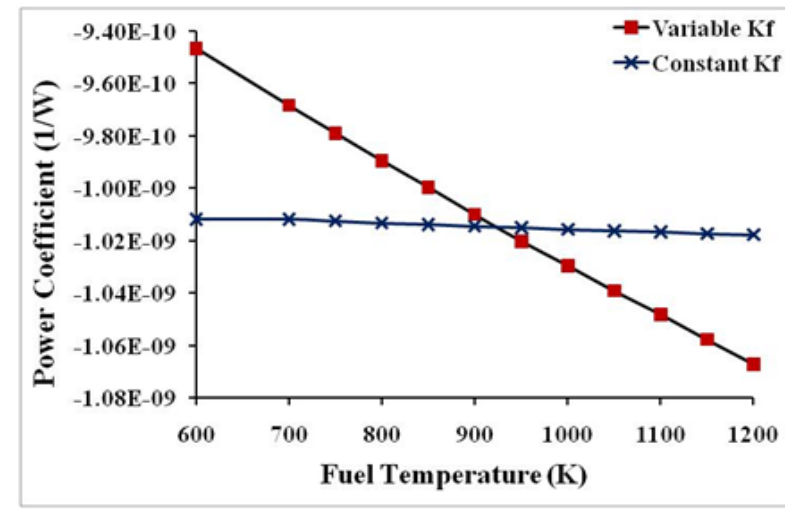

Annular Fuel

Figure (11): Power Coefficient

\section{Conclusions}

- In this paper two assemblies, designed for OPR-1000, one with solid fuel and the other uses annular fuel, were simulated at $100 \%$ power, at BOC, using MCNP6, and the model was verified using the results of a previous study.

- The MAKXSF code was used to generate new libraries with temperature adjusted cross sections.

- Results showed that the use of temperature- adjusted libraries, to determine the multiplication factor, gave more realistic results than the case of the use of regular libraries, in the case of change in fuel temperature change. On the other hand, in the case of moderator temperature, the difference between the results of temperature adjusted and regular libraries was insignificant for the range of temperatures under consideration.

- The resulting average FTC, and MTC trends agree with previous studies on annular fuel

- The results for prompt reactivity and power coefficients showed that the annular fuel have more negative values than the solid fuel, which implies better inherent safety.

- The importance of detailed modeling taking into consideration the thermophysical properties of fuel was clarified.

\section{References}

1. E.E., Lewis, "Fundamentals of Nuclear Reactor Physics”. Academic Press, 2008.

2. Lamarsh J. R., Baratta A. J., "Introduction to Nuclear Engineering”, Prentice Hall Inc. USA. 2003.

3. International Atomic Energy Agency, "Status of advanced light water reactor designs”, AEATECDOC-1391, Vienna, 2004.

4. Liang Zhang, "Evaluation of High Power Density Annular Fuel Application in the Korean OPR-1000 Reactor”, Master of Science in Nuclear Science \& Engineering at the Massachusetts Institute of Technology, June 2009.

5. Chang-Hwan Shin, Tae-Hyun Chun, DongSeok Oh, Wang-Kee In,” Thermal hydraulic performance assessment of dual-cooled annular nuclear fuel for OPR-1000”, Nuclear Engineering and Design 243 (2012) pp. 291300

6. F. Faghihi , M. Saidi nezhad, "Two safety coefficients for a typical $13 \times 13$ annular fuel assembly”, Progress in Nuclear Energy 53 (2011) 250-254.

7. Erfani Nia , F. Faghihi, K. Hadad, "Prompt and power reactivity coefficients for the next generation VVER-1000 reactor including hexagonal assemblies and annular fuels”, Progress in Nuclear Energy 61 (2012) 41-47

8. Denise B. Pelowitz, “MCNP6 USER'S MANUAL Version 1.0”, LA-CP-13-00634, Rev. 0, Los Alamos National Laboratory (2013). 
9. Forrest B. Brown,” Description and Input Manual for the MAKXSF Code, LA-UR-067002,(2006)

10. Yong Sik YANG, et. al.,” Evaluation of a Dual-Cooled Annular Fuel Heat Split and Temperature Distribution”, Journal of Nuclear Science and Technology, Vol. 46, No. 8, p. 836-845 (2009)

11. Kyung-Hoon Lee et al., "Assessment of the HELIOS Code for the OPR-1000 Assembly with an Annular Fuel”, Transactions of the Korean Nuclear Society Autumn Meeting, Korea, 2008.

12. E.E., Lewis, "Nuclear Power Reactors Safety", John Wily \& Son, Inc., 1977.

13. W. G. Luscher and K. J. Geelhood, "Material Property Correlations: Comparisons between FRAPCON-3.5, FRAPTRAN-1.5, and MATPRO”, NUREG/CR-7024, Rev. 1. 2014

14. Mahmoud Massoud, "Engineering Thermofluids, Thermodynamics, Fluid Mechanics, and Heat Transfer”, SpringerVerlag Berlin Heidelberg, 2005.

15. Yangbin Deng, et. al., "Mechanism study and theoretical simulation on heat split phenomenon in dual-cooled annular fuel element”, Annals of Nuclear Energy 94, pp. 44-54, (2016).

16. Glasstone, S., and Sesonke, A., "Nuclear /reactor Engineering: Reactor System Engineering”, Chapman\& Hall Inc., 1994.

17. C. Ronchi, M. Sheindlin, M. Musella, and G. J. Hyland "Thermal conductivity of uranium dioxide up to $2900 \mathrm{~K}$ from simultaneous measurement of the heat capacity and thermal diffusivity” Journal of Applied Physics, volume 85, number 2, 15 January 1999.

18. Hagrman, T. (ed.), SCDAP/RELAP5/MOD 3.1 Code manual: MATPRO - a library of materials properties for light-water-reactor accident analysis, NUREG/CR-6150, EGG2720, Vol. 4 (1995).

19. F. P., Incropera, D. P., Dewitt, "Fundamentals of Heat and Mass Transfer”, John, Wiley \& Sons, (2011)

20. Jay L. Devore, "Probability and Statistics for Engineering and the Sciences”, Boston, MA: Cengage Learning. pp. 508-510, (2011)

21. M.S. Kazimi, "High Performance Fuel Design for Next Generation PWRs: Final Report”, MIT-NFC-PR-082, January, (2006). 